\title{
Management Dilemma in Case of Abdominal Pregnancy: A Case Report
}

\author{
Alpana Singh, Vandana Mishra*, Daisy Arun, Amita Suneja, Abha Sharma \\ UCMS \& GTB Hospital, New Delhi, India \\ Email: drvanu123@gmail.com
}

Received 24 August 2014; revised 20 September 2014; accepted 15 October 2014

Academic Editor: Francisco Alameda Quitllet, University of Barcelona, Spain

Copyright (C) 2014 by authors and Scientific Research Publishing Inc.

This work is licensed under the Creative Commons Attribution International License (CC BY). http://creativecommons.org/licenses/by/4.0/

(c) (i) Open Access

\begin{abstract}
Introduction: Abdominal pregnancy is a rare form of ectopic pregnancy demanding high index of suspicion for diagnosis. We present a case of secondary abdominal pregnancy which was missed at a peripheral centre and referred to us with laparostomy wound after attempts were made to terminate it without proper diagnosis which resulted in excessive bleeding. Case Presentation: A 30year-old primigravida was referred to us from a private clinic with a laparostomy wound. She had gone to the private clinic for termination of her 5-month-old pregnancy. Medical method was attempted initially failing which surgical evacuation was planned at second visit which resulted in excessive bleeding. The patient was opened up, fetus was removed from assumed uterine cavity and attempted to remove the placenta caused torrential bleeding. The abdominal cavity was packed and she was referred to a higher centre. Here she was taken up for re-exploration; ectopic sac was separated from neighboring structures, right cornu was found ruptured and was repaired. The patient also had wound dehiscence on post op day 7 for which secondary abdominal closure was done. Conclusion: Secondary abdominal pregnancy poses as a challenge to clinicians working in remote areas with limited diagnostic facilities. The condition may be life threatening if not handled meticulously.
\end{abstract}

\section{Keywords}

Secondary Abdominal Pregnancy, Cornual Rupture, Laparostomy Wound

\section{Introduction}

Abdominal pregnancy is one of the rarest and the most dangerous variety of ectopic pregnancy constituting ap-

"Corresponding author.

How to cite this paper: Singh, A., Mishra, V., Arun, D., Suneja, A. and Sharma, A. (2014) Management Dilemma in Case of Abdominal Pregnancy: A Case Report. Open Journal of Obstetrics and Gynecology, 4, 899-902. 
proximately $1 \%$ of all ectopic pregnancies [1]. The incidence of abdominal pregnancy differs in various literatures, ranging from 1:10,000 to 1:30,000 pregnancies [2]. It can be primary where fertilised ovum implants on an abdominal organ [3]. But most are secondary where fertilised ovum first implants in the uterus, ovary or tube subsequently implanting in the peritoneal cavity after tubal abortion, rupture or uterine scar rupture [4]. It carries very high maternal mortality and morbidity, especially if the condition is not diagnosed and managed appropriately. Maternal mortality can be as high as $20 \%$ primarily due to torrential bleeding from partial or total placental separation from its attachment to the uterine wall, bowel, mesentery, other abdominal viscera or ligaments [5]. Morbidity is also high resulting from bleeding, infection, DIC, anemia, pulmonary embolism, fistula formation, etc. [6]. These pregnancies rarely get to term resulting in extraction of a dead fetus. Another challenge for fetus is the very high incidence of congenital malformations [3]. The condition is reported to be higher in developing countries, probably because of the greater prevalence of pelvic inflammatory disease in these areas [7]. Abdominal pregnancies pose a diagnostic dilemma unless the clinician has a high index of suspicion. Here we present an interesting case of a successful surgical management of a misdiagnosed abdominal pregnancy following cornual rupture after an attempted medical termination of pregnancy.

\section{Case Report}

A 30-year-old primigravida belonging to poor socio-economic status presented to our emergency department with a laparostomy wound with surgical packs in abdomen. At the time of presentation she was hemodynamically stable. She had presented to a private clinic for termination of her pregnancy of 5-month duration. She had no previous antenatal visits or ultrasound done. A medical termination was attempted by some oral drug (probably misoprostol) which failed. The patient came back again after 2 weeks for termination of her continuing pregnancy. In this visit surgical evacuation by suction evacuation was tried which resulted in heavy bleeding per vaginum. The patient was taken up for an emergency laparotomy there. On opening the abdomen dense adhesions were encountered; uterus could not be delineated completely. After some degree of adhesiolysis the fetus was removed assuming it to be inside the uterine cavity. Attempts to remove the placenta resulted in heavy bleeding, patient's vitals began to deteriorate, her blood pressure dropping down to $60 / 40 \mathrm{mmHg}$ when it was decided to abort the procedure. Abdominal packing was done and after primary resuscitative efforts the patient was asked to go to a higher centre for further management. Due to poverty and inaccessibility of transport facilities the patient had to stay at home for two days where she even received food orally.

She came to our hospital after nearly 48 hours for closure of her abdominal wound. At presentation, her general condition was stable. She was pale, nonicteric. On per abdominal examination open wound was seen secured with binders. Per speculum examination cervix and vagina were normal. In per vaginal examination uterine size could not be assessed because of open abdominal wound and bilateral adnexa were normal. Her haemoglobin was $7.6 \%$, platelet count was 1.6 lac, blood urea was $52 \mathrm{mg} / \mathrm{dl}$, serum creatinine $0.77 \mathrm{mg} / \mathrm{dl}$. Liver function test and coagulation profile were normal. She was found to be reactive for hepatitis B surface antigen. She was planned for re-exploration and 2 units of packed cell transfused preoperatively. Intraoperatively parietal peritoneum was found adherent to margins of the wound and below with omentum and gut loops. The assistance of a surgeon was sought and after meticulous dissection amniotic sac with necrosed placenta was found attached to omentum and gut loops. The ectopic sac was separated from adjacent structures and removed in piecemeal with the necrotic placenta. A bulky uterus was visualised after dissection of the sac. Right cornu was adherent to large colon, dissected and found to be ruptured. It was excised and repaired. Both the tubes and ovaries were adhered with pelvic structures. Her early post operative period was uneventful but she developed wound dehiscence on day 7 post op for which her secondary abdominal closure was done. Her total duration of hospital stay was 28 days. The histopathology examination of the specimen from gestational sac revealed presence of chorioamnionitis.

\section{Discussion}

Encountering a case of abdominal pregnancy is a rare event for any clinician which carries extremely high maternal and even higher perinatal mortality. Its diagnosis is difficult and requires a high index of suspicion for prompt diagnosis and timely intervention to prevent life threatening complications.

Primary abdominal pregnancy where implantation occurs in the peritoneal cavity is a rare phenomenon. Most 
of the cases are of secondary nature where the fetus with placenta gains access to the peritoneal cavity after escaping through ruptured uterine scar or tube 4 . A case of secondary abdominal pregnancy following rupture of one cornu of a bicornuate uterus was reported by Saha et al. [8]. Mohanty et al. reported a 17-week pregnancy in the peritoneal cavity after rupture of rudimentary horn of uterus [9]. A case of advanced abdominal pregnancy following rupture of rudimentary horn of uterus was reported by Desai et al. [10]. Advanced abdominal pregnancy after uterine scar rupture has been reported by Hamid et al. [11]. Full term abdominal pregnancy after ruptured ectopic has also been reported by Dahab et al. [12]. An observation of 10 cases of advanced abdominal pregnancy has been described by Rehman et al. [13]. The laparotomy findings in our case suggest it to be a case of uteroabdominal pregnancy following uterine rupture at time of termination of pregnancy. The embryo might have migrated through the rent in cornu of uterus to establish in the peritoneal cavity. It is most likely a case of attempted termination of pregnancy by untrained personnel. A timely referral to a higher centre might have led to earlier diagnosis. Ultrasound may be helpful during early stages of gestation but can be disappointing in later stages. MRI and CT scan are helpful in the diagnosis in later stages, unfortunately these advanced technologies are unavailable in most parts of the third world [14]. Teng et al. reported an interesting case of abdominal pregnancy in which MRI played a decisive role in its diagnosis [15].

\section{Conclusion}

This is a report of extrauterine abdominal pregnancy gaining access to peritoneal cavity probably after perforation during attempted termination of pregnancy. Unsafe abortions continue to be rampant in rural and low resource settings, the diagnosis of such conditions being more difficult due to unavailability of advanced technologies like ultrasound, CT or MRI. Information, education and communication activities need to be intensified to make abortion safe. MTP services should be more widely available. Obstetricians need to be alert of such conditions, seeking timely expert help to reduce the associated morbidity and mortality.

\section{References}

[1] Ludwig, M., Kaisi, M., Bauer, O. and Diedrich, K. (1999) The Forgotten Child-A Case of Heterotopic, Intra-Abdominal and Intrauterine Pregnancy Carried to Term. Human Reproduction, 14, 1372-1374. http://dx.doi.org/10.1093/humrep/14.5.1372

[2] Yildizhan, R., Kurdoglu, M., Kolusari, A. and Erten, R. (2008) Primary Omental Pregnancy. Saudi Medical Journal, 29, 606-609.

[3] (2008) Ectopic Pregnancy. In: Protap, K. and Narendra, M., Eds., Jeffcoate’s Principles of Gynaecology, JP Brothers Med Pub., New Delhi, 157-159.

[4] King, M., Bewes, P.C., Cairns, J. and Thornton, J., Eds. (2014) Chapter 8. Abdominal Pregnancy in Primary Surgery. Vol. 1, Non-Trauma.

[5] Ang, L.P., Tan, A.C. and Yeo, S.H. (2000) Abdominal Pregnancy: A Case Report and Literature Review. Singapore Medical Journal, 41, 454-457.

[6] Martin Jr., J.N., Sessums, J.K., Martin, R.W., Pryor, J.A. and Morrison, J.C. (1988) Abdominal Pregnancy: Current Concepts of Management. Obstetrics \& Gynecology, 71, 549-557.

[7] Opare-Addo, H.S. and Deganus, S. (2000) Advanced Abdominal Pregnancy: A Study of 13 Consecutive Cases Seen in 1993 and 1994 at Komfo Anokye Teaching Hospital, Kumasi, Ghana. African Journal of Reproductive Health, 4, 2839. http://dx.doi.org/10.2307/3583240

[8] Saha, S.K., Adhikari, S., Sanjay, M.K., et al. (1997) Bicornuate Uterus with Secondary Abdominal Pregnancy Following Rupture of One Cornu. The Journal of Obstetrics \& Ganecology of India, 47, 267.

[9] Mohanty, S. and Mohanty, M. (2000) Pregnancy in Rudimentary Horn of Bicornuate Uterus. The Journal of Obstetrics \& Ganecology of India, 30, 50-85.

[10] Desai, B.R., Patted, S.S., Pujar, Y.V., et al. (2005) Advanced Secondary Abdominal Pregnancy Following Rupture of Rudimentary Horn. The Journal of Obstetrics \& Ganecology of India, 55, 180.

[11] Hamid, A.N., Begum, R., Sultana, Z. and Akhter, N. (2010) Advanced Abdominal Pregnancy: A Case Report. Journal of Chittagong Medical College Teachers' Association, 21, 74-76.

[12] Dahab, A., Aburass, R., Shawkat, W., Bagbi, R., Essa, O., et al. (2011) Full Term Extrauterine Abdominal Pregnancy: A Case Report. Journal of Medical Case Reports, 5, 531. http://dx.doi.org/10.1186/1752-1947-5-531 
[13] Rehman, M.S., Al-Suleiman, S.A., Rahman, J., et al. (1982) Advanced Abdominal Pregnancy-Observation in 10 Cases. Obstetrics \& Gynecology, 59, 366-372.

[14] Karat, L.S. (2007) Viable Abdominal Pregnancy. The Journal of Obstetrics \& Ganecology of India, 57, 169-170.

[15] Cunningham, F., Gant, N., Leveno, K., et al. (2001) Williams Obstetrics. Ectopic Pregnancy, 21, 899-902. 
Scientific Research Publishing (SCIRP) is one of the largest Open Access journal publishers. It is currently publishing more than 200 open access, online, peer-reviewed journals covering a wide range of academic disciplines. SCIRP serves the worldwide academic communities and contributes to the progress and application of science with its publication.

Other selected journals from SCIRP are listed as below. Submit your manuscript to us via either submit@scirp.org or Online Submission Portal.
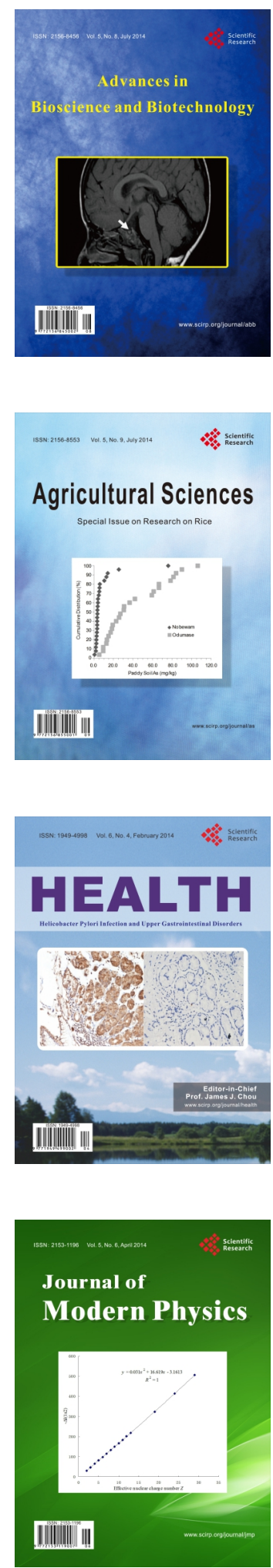
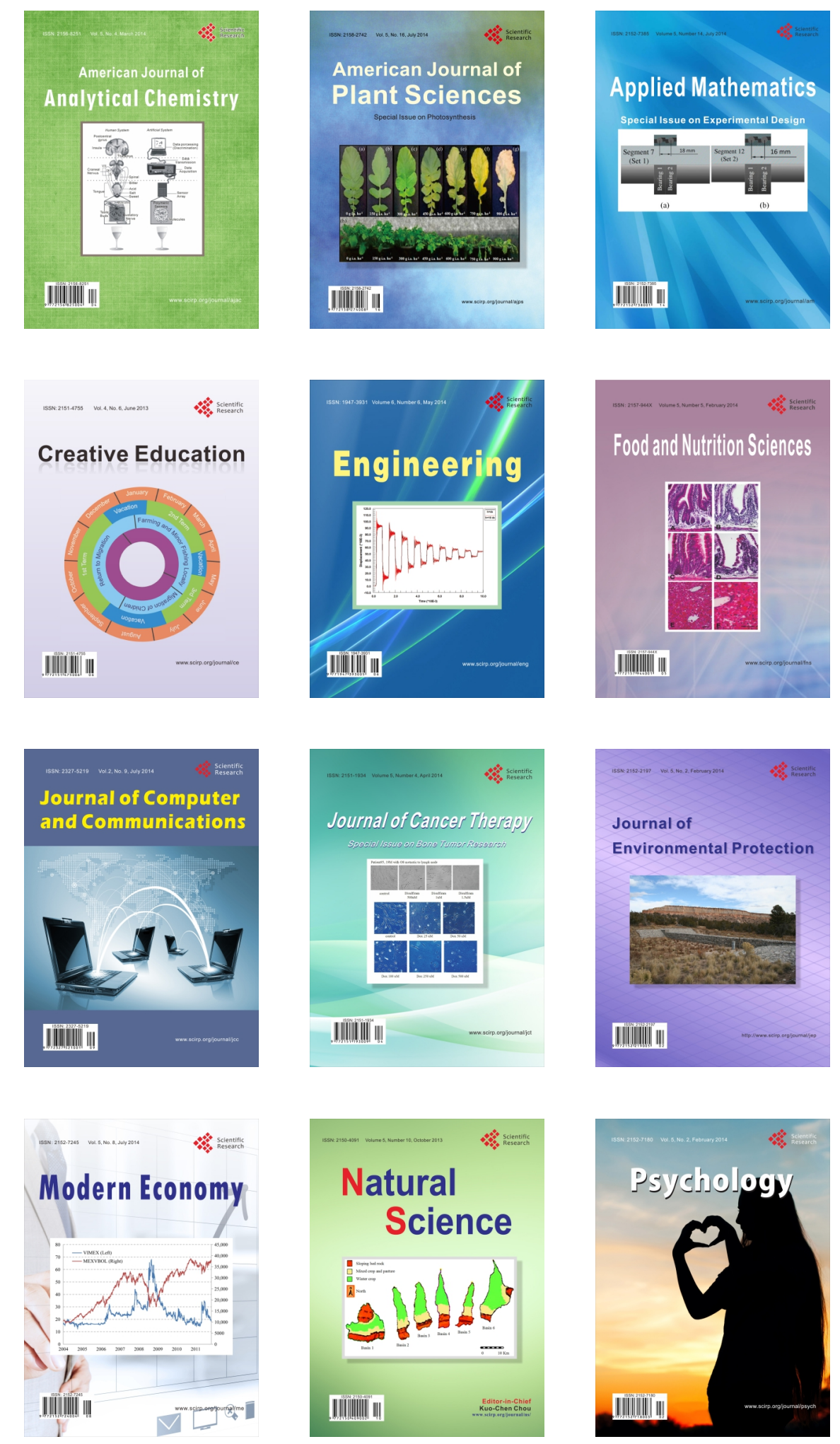